\title{
Population Growth and Aging in Finland
}

\author{
MAURINIEMINEN, M.A.
}

Senior Adviser

Population Statistics, Statistics Finland

\section{Abstract}

The size and structure of a population depend on the development of fertility, mortality and migration. Over the past few decades, population growth in the industrialised countries has been low. This has resulted from falls in fertility and mortality. The age groups born yearly have been smaller than their predecessors and falling mortality has meant that the number of years people can expect to live has increased.

A quick glance at the Finnish age pyramid gives clear signals of what the future holds. The development of fertility has influenced the shape of the pyramid most. The distinct bulge of the large age groups has had a crucial impact on the Finnish social and economic development over the past 50 years, and its effects will continue to be seen far into the future.

The decline in the Finnish fertility rate coincides with the country's economic growth. This has also happened in many other countries. Longer lifetime increases the number of old people so, consequently, the demand for services directed to them also increases. Men's higher mortality shows in many ways in society, from issues connected with living alone to the use of health care services. At the end of 1997, the population of Finland was $5,147,349$ and the annual population growth was 0.2 percent. If the predictions of the population projection come through, the population of Finland will reach its peak in 2021, when it is forecast to be 5,294,000, in other words 147,000 more than today. After this, the Finnish population will start to decline annually. The natural population growth, i.e. the difference between births and deaths, will swing to negative as early as 2015.

Today, the total number of persons aged over 65 is slightly over 750,000, of whom the majority, or 62 percent, are women. In future years, the development of the number of old persons will, in the first place, be influenced by the predicted lower mortality rate, which will increase people's life expectancy. The number of person aged over 65 will be at its highest in the early 2030s, when estimates put it at 1,375,000. This is over 80 percent higher than today. The increase in the number of old persons will have an impact in the future, as more people than today will be pensioners. Therefore, the demand for the services directed to this age group will also increase and society must be able to satisfy this demand.

When the population ages at the speed it is doing in Finland today, for example, our social policies face a totally new challenge. The aging of the population naturally leads to 
an increase in the demand for those services that are targeted direct to old people. A watertight social security system has been developed in Finland over the past years, which follows a person from cradle to grave. The system was created at a time when there was no shortage of payers and nobody saw that in a couple of decades the Finnish age structure would be totally different from what it is today. There will certainly be a much larger proportion of the population in the side of those being cared for than in that of the carers. In addition, a vast majority of those needing care will also be pensioners.

Keywords: Aging, pension, age structure, population projection

\section{Introduction}

The size and structure of a population depend on the development of fertility, mortality and migration. Over the past few decades, population growth in the industrialised countries has been low. This has resulted from falls in fertility and mortality. The age groups born yearly have been smaller than their predecessors and falling mortality has meant that the number of years people can expect to live has increased.

However, the slow population growth in the industrialised countries is counterbalanced by the rapid growth of population in the developing countries, attributable to a large extent to their considerably higher fertility rates. Today, almost half of the population in many developing countries is aged under 15 years. As a consequence, the proportions of the different population groups of children, people of working age and elderly people are different in industrialised countries from those in developing countries. While in the industrialised countries children form an increasingly small proportion of the population and the proportion of elderly persons is growing, in the developing countries these proportions are exactly reversed.

In industrialised and developing countries alike, the ageing of the population manifests itself as a strong increase in the number of older people. At the moment, the proportion of elderly people of the total population is approximately 14 percent in the industrialised countries and approximately five percent in developing countries. However, there will be strong future growth in the number of elderly people in both the industrialised and developing countries.

The figures of the UN's population projections that show that the world's population is ageing, are also perhaps the clearest indicators of the fact that the gap between the industrialised and developing countries is widening with respect to the ageing population. While in the industrialised countries the total size of the population aged over 65 is 158 million at the moment, it is forecast to rise to 264 million by the year 2030. This is an increase of 67 percent. Today, the number of persons over 65 who live in the developing countries is 213 million but it is estimated to rise to 670 million by 2030 , meaning an increase of 215 percent.

Because the number of elderly people will increase considerably faster in the coming years than in the preceding years, it is, of course, appropriate to consider the consequences of this development. Obviously, an increase in the number of old people will increase the demand 
for old-age, social and health care services. If a comparison is made between the industrialised and developing countries, the ageing of the population is certainly going to present a bigger future challenge to the developing countries than to the industrialised countries.

All industrialised countries have at least some kind of pensions system and are able to offer good health care services. By comparison, elderly people in many developing countries still depend on the care of the family or relatives. In many countries, this system is starting to crumble because of migration and the elderly are often left completely without any care.

\section{The age pyramid - the future in a looking-glass}

A quick glance at the Finnish age pyramid gives clear signals of what the future holds. The development of fertility has influenced the shape of the pyramid the most. The distinct bulge of the large age groups has had a crucial impact on the Finnish social and economic development over the past 50 years, and its effects will continue to be seen far into the future.

Figure 1. Age pyramids of the population 1950, 1997, 2010 and 2030
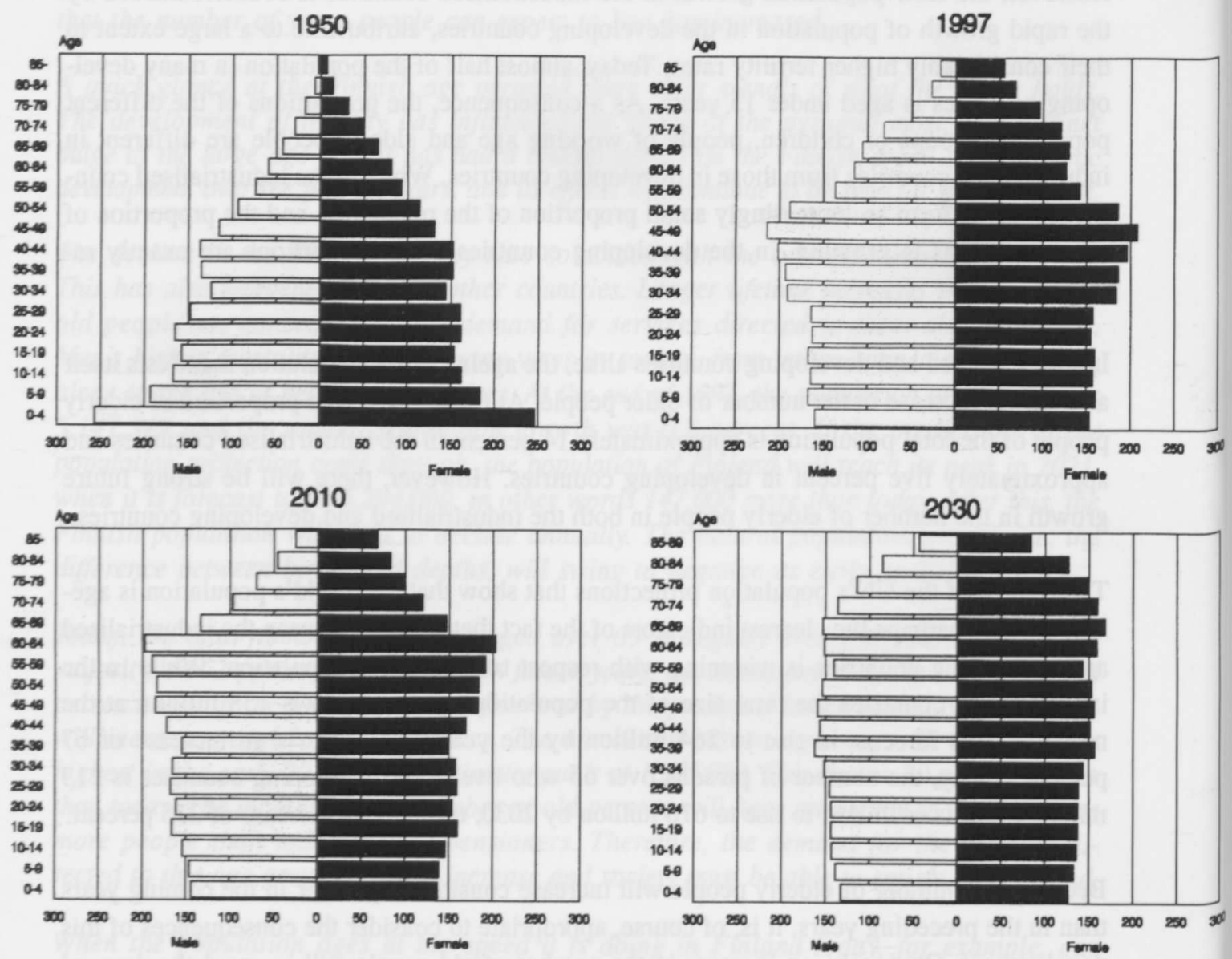
Those born between 1946 and 1950 are often referred to as the large age groups, for over this five-year period, annual birth-rates were the highest in Finnish history. The all-time largest age group of 108,168 children were born in 1947, and the total fertility rate was 3.5 . In the Finnish age pyramid, those born between 1946 and 1950 show as a distinct bulge, because in the years prior to the war fertility had been falling and during the uncertain war years fertility often swung from one extreme to the other. Although fertility then started to fall annually from 1947 onwards, the large age group of those born between 1946 and 1950 continues to form the largest bulge in the pyramid. (See: Miettinen et al. 1998, 15.)

In 1969 the total fertility rate fell below the reproduction level for the first time and has remained below it ever since. After the mid-1970s, annual fluctuations in fertility have been minimal. In 1997 the total fertility rate in Finland was 1.75 , which was among the highest in the EU countries.

Considering the reproduction of population, where the total fertility rate should not fall below 2.1, the last generation to have reproduced itself were women born between 1939 and 1940. The average number of children they bore exceeded the 2.1 threshold needed for population reproduction. The generations after that have not borne the number of children needed for reproducing the population. Thus, the population increase achieved through fertility has been gradually slowing down from one year to the next.

The decline in the Finnish fertility rate coincides with the country's economic growth. This has also happened in many other countries. Various support measures offered by the society, such as child allowances and tax concessions, have failed to raise the fertility rate - nor were they even designed to do this. They may have produced temporary increases in fertility, but the long-term effects of these different support measures have been fairly insignificant.

People's attitudes and values, however, are significant, for fertility often declines when growing emphasis is put on material values, causing families to decide on a small number of children.

\section{Longer lifetime means more old people}

The number of old people depends mostly on the size of the age groups that are reaching old age, and on the development of mortality. Over the past few decades, mortality has been falling steadily. While the life expectancy of male children born after the Second World War was calculated to be 59 years and that of female children 66 years, in 50 years mortality has declined so much that the life expectancy of male children born in 1997 was calculated to be 73 years and that of female children 81 years. 
Table 1. Life expectancy in 1945-1997

$\begin{array}{lll}\text { Years } & \text { Male } & \text { Female } \\ 1946-50 & 58.4 & 65.8 \\ 1971-76 & 66.8 & 75.3 \\ 1997 & 73.4 & 80.5\end{array}$

Source: Life tables 1945-1997, Population Statistics, Statistics Finland.

There is a clear difference in mortality between men and women - on average, Finnish women today live eight years longer than Finnish men. This is directly reflected in the number of old people in that the ageing female population far exceeds the male one. This can also be observed from the age pyramid in which there are more women at the top.

A longer life-span increases the number of old people, so, consequently, the demand for services directed to them also increases. Men's higher mortality shows in many ways in society, from issues connected with living alone to the use of health care services.

\section{Effects of migration on age structure still minor}

Finland has never been a country to attract large numbers of foreign immigrants. Well into the 1980 s, the majority of immigrants into Finland were Finnish emigrants returning back from Sweden. Migration has had little impact on the age structure of the population of Finland.

Although it left no clearly detectable dent in the Finnish age pyramid, tens of thousands of Finns emigrated to Sweden especially at the turn of the 1960s and 1970s. The numbers were so great that in 1969 and 1970 the population of Finland went down for the first time in peace time since the Great Famine in the 19th century. There are still over 200,000 Finnish-born people living in Sweden today. These persons are missing from the Finnish age pyramid (Korkiasaari and Söderling, 263).

At the beginning of the 1990s, the character of the migration into Finland changed. Finns returning from Sweden were no longer in the majority, which now consisted of people from areas belonging to the former Soviet Union and from Somalia instead. Returning descendants of Ingrian emigrants and refugees from a handful of countries increased the foreign population of Finland manyfold compared to the 1980s. Towards the end of 1997 , there were 80,600 foreign-born persons living in Finland - less than one fifth of them refugees and one fifth returning Ingrian emigrants and their families. At the moment, foreign citizens account for 1.6 percent of the Finnish population (Nieminen, 1998, 6).

This foreign-born population has very little impact on the age structure of the Finnish population. Although most of the immigrants are of working age, their employment has proven difficult because their immigration to Finland coincided with the country's worst years of unemployment. Their employment situation has improved only marginally. In 1997, the overall 
unemployment rate for the foreign-born population was 43 percent and, especially with respect to the largest refugee groups, it even exceeded 70 percent.

Today the relative proportion of immigrants in the total Finnish labor force is negligible, amounting to only just over one per cent. However, if Finland should face an unexpected labor shortage, deliberate immigration of foreign labor could become a factor worthy of attention.

However, very selective importation of labor to Finland would seem impossible at the moment. Finland is committed to receiving annually 2,000 returning descendants of Ingrian emigrants plus 1,000 refugees. Without further training these groups are unlikely to solve the labor force problems of the most needy areas.

\section{The population goes on aging...}

Two main factors will have an impact on the number of elderly people in the future: the age structure and the development of mortality. Yet, it can be expected that in the coming years the number will also be marginally influenced by migration, if people who in the past emigrated from Finland return to spend their retirement in Finland. There is already some, although minor, evidence of this type migration. Most of the foreign-born old people were born in Sweden, followed by those born in the USA. For the main part they are descendants of Finnish emigrants.

Therefore, it can be said that the number of old people in the population depends on the development of mortality and, of course, on the present age structure. In what follows the population trends are examined according to the population projection published by Statistics Finland in 1998 (Population 1998:6).

The presumptions in the population projection about the trends in fertility, mortality and migration are as follows:

\section{Fertility}

During the past two decades, the total fertility rate has bottomed out in 1973 when it was 1.50, and peaked in 1993 and 1995 when it was 1.85 . From 1973 onwards, the rate has remained at approximately 1.70 . However, the population projection puts the assumed total fertility rate slightly above the normal for the projection period. (Miettinen et al. 1998, 16.)

Although fertility has fluctuated annually, the changes have not been very significant. The population projection does not attempt to estimate the annual fluctuations of the fertility rate but assumes that the rate will remain at the past few years' level and that total fertility will be 1.75 for the entire projection period.

\section{Mortality}

Both men's and women's mortality has declined in the 1980s and 1990s. Men's mortality has fallen slightly more than women's. On the basis of past development, mortality is estimated 
to fall so that by 2030 men's life expectancy will have gone up from its present 73.4 years to 78.7 years. At the same time, women's life expectancy is estimated to increase from the present 80.5 years to 84.0 years. The difference in the life expectancy between the sexes is forecast to contract from the present seven years to 5.3 years over the projection period.

\section{Migration}

Almost throughout the 1980 s and 1990 s, migration to Finland has shown surplus. Fluctuations in net migration have been influenced more by the development of immigration than emigration. Ever since the early 1980 s, development has been far more stable in immigration than in emigration. Over the projection period, net migration is forecast to show an annual surplus of 4,000 .

\section{Population growth will slow down and swing to negative}

At the end of 1997 , the population of Finland was 5,147,349 and the annual population growth was 0.2 percent. If the predictions of the population projection come through, the population of Finland will reach its peak in 2021, when it is forecast to be 5,294,000 - in other words 147,000 more than today. After this, the Finnish population will start to decline annually. The natural population growth, i.e. the difference between births and deaths, will swing to negative as early as 2015 .

Although the quantitative development of the population is of no great significance today - at least not in the short-term - the development of the population's age structure does play a considerably more important role. It is quite evident that the need for many services is agerelated. Certain services are produced for people of certain age and, equally, the demand for certain services changes along with age.

The increase in the number of old persons will have an impact in the future, as more people than today will be pensioners. Therefore, the demand for the services directed to this age group will also increase and society must be able to satisfy this demand.

The growing number of old persons will generate increases in the demand for old age, health and social care services, in particular. As the proportion of old people of the total population continues to increase, the question of how the needs of the people of different age groups should be prioritised will also have to be considered. This may generate tension between the different generations. While approximately 14 percent of the population today are aged over 65 , their proportion is predicted to be nearly 26 percent in 2030 . This puts our society faceto-face with a totally new challenge of having to cope with a situation where one quarter of the population consists of old people. 
Table 2. Population growth (\%) (basic year 1997) by age 1997-2030

$\begin{array}{lrrrrrrrrrr}\text { Total } & 0-14 & \% & 15-64 & \% & 65+ & \% & 80+ & \% & \text { Total } & \% \\ 1997 & 961350 & & 3433511 & & 752488 & & 168751 & & 5147349 & \\ 2010 & 860121 & -10,5 & 3494670 & 1,8 & 904882 & 20,3 & 228919 & 35,7 & 5259673 & 2,2 \\ 2030 & 819177 & -14,8 & 3082566 & -10,2 & 1355871 & 80,2 & 400572 & 137,4 & 5257614 & 2,1 \\ 2050 & 746853 & -22,3 & 2880825 & -16,1 & 1313703 & 74,6 & 464155 & 175,1 & 4941381 & -4,0 \\ \text { Male } & & & & & & & & & & \\ 1997 & 490594 & & 1735040 & & 283464 & & 45980 & & 2509098 & \\ 2010 & 438582 & -10,6 & 1763082 & 1,6 & 376377 & 32,8 & 72527 & 57,7 & 2578041 & 2,7 \\ 2030 & 417747 & -14,8 & 1556943 & -10,3 & 602648 & 112,6 & 155006 & 237,1 & 2577338 & 2,7 \\ 2050 & 380894 & -22,4 & 1457691 & -16,0 & 599484 & 111,5 & 189952 & 313,1 & 2438069 & -2,8 \\ \text { Female } & & & & & & & & & & \\ 1997 & 470756 & & 1698471 & & 469024 & & 122771 & & 2638251 & \\ 2010 & 421539 & -10,5 & 1731588 & 1,9 & 528505 & 12,7 & 156392 & 27,4 & 2681632 & 1,6 \\ 2030 & 401430 & -14,7 & 1525623 & -10,2 & 753223 & 60,6 & 245566 & 100,0 & 2680276 & 1,6 \\ 2050 & 365959 & -22,3 & 1423134 & -16,2 & 714219 & 52,3 & 274203 & 123,3 & 2503312 & -5,1\end{array}$

Source: Population projection by municipalities 1998-2030. Statistics Finland, Population 1998:6

\section{Number of old age pensioners will increase}

Today, the total number of persons aged over 65 is slightly over 750,000, of whom 62 percent, are women. In future years, the development of the number of old persons will, in the first place, be influenced by the predicted lower mortality rate, which will increase people's life expectancy. However, the growth in the number of elderly people will be mainly attributable to the current population structure, because the age groups born just after the war will reach old age pension age in the 2010 s, when the growth in the number of old people will also reach its peak.

The number of person aged over 65 will be at its highest in the early 2030 s, when estimates put it at $1,375,000$. This is over 80 percent higher than today.

During the same period up to the early 2030 s, there will be considerably stronger growth in the number of old men than old women. This is because men's mortality is predicted to fall more rapidly than women's. This, in turn, is due to the fact that women's mortality today is already low and is not expected to continue to fall as strongly as it has done up to now.

This development also follows from the fact that the difference in mortality between men and women is forecast to narrow down over the next few decades. Thus men's lowered mortality will increase their life expectancy and the number of men over 65 will grow faster than that of women. 


\section{Number of persons over 80 will double}

While the number of persons over 65 will reach its peak in the 2030 s, the number of the very old persons aged over 80 will continue to grow right to the end of the 2040 s.

While persons aged over 80 today number almost 169,000 , by the year 2030 the number will have increased to 400,000 , in other words doubled. The number of very old men will have tripled and that of women doubled. This development will, naturally, be felt in many sectors of society. Although it is to be expected that elderly persons will remain healthy longer in the future, this will not significantly reduce the demand for the services that are offered to those over 80 . The increased number of the very old people will sustain ample demand for these services.

As already stated above, ageing is a global phenomenon, but it occurs at different speeds in different countries. In countries like Finland, where fertility has been above average in certain years, ageing may surge up at times. This is what will happen in Finland after 2010, when the large, post-war age groups pass 65 years.

In many countries the age structure has been repaired by importing labor force from abroad, as has happened in Germany, for example. In the age structure, the exceptional war years show as small age groups and the war-time losses of men will also be reflected in it in the future.

If ageing is to be understood as an increase in the proportion of old persons of the total population, the present low fertility is changing the shape of the age pyramid in many industrialised countries so that the proportion of children of the total population continues to decrease while that of old persons keeps growing.

Over the coming years, the proportion of elderly people of the total population will increase distinctly in the EU countries. This means that the population will be ageing. While at the moment Sweden has the most aged population in the EU, the situation will change in the coming years. Low fertility and declines in the population of working age will become visible as increases in the proportion of old persons in all countries. In 2030, this proportion will amount to nearly one quarter of the population.

While persons aged over 65 living in the EU today number 57 million, their number is estimated to have risen to 93 million by 2030 . By that time every fourth person living in the EU will be over 65 . 
Figure 2. Percentage of old people of the total population in EU countries, 1995-2030

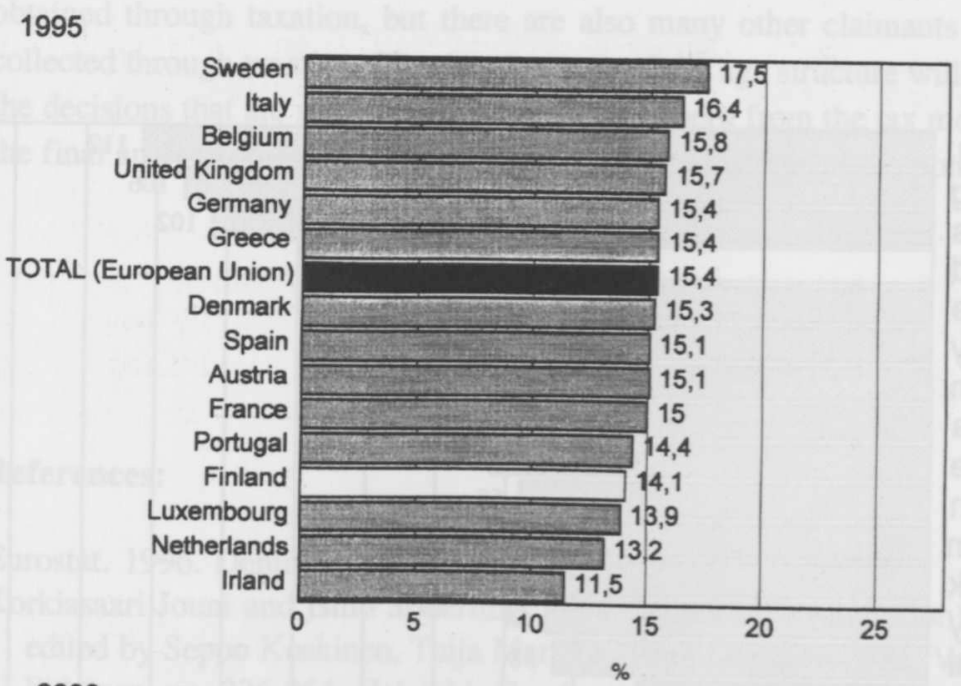

2030

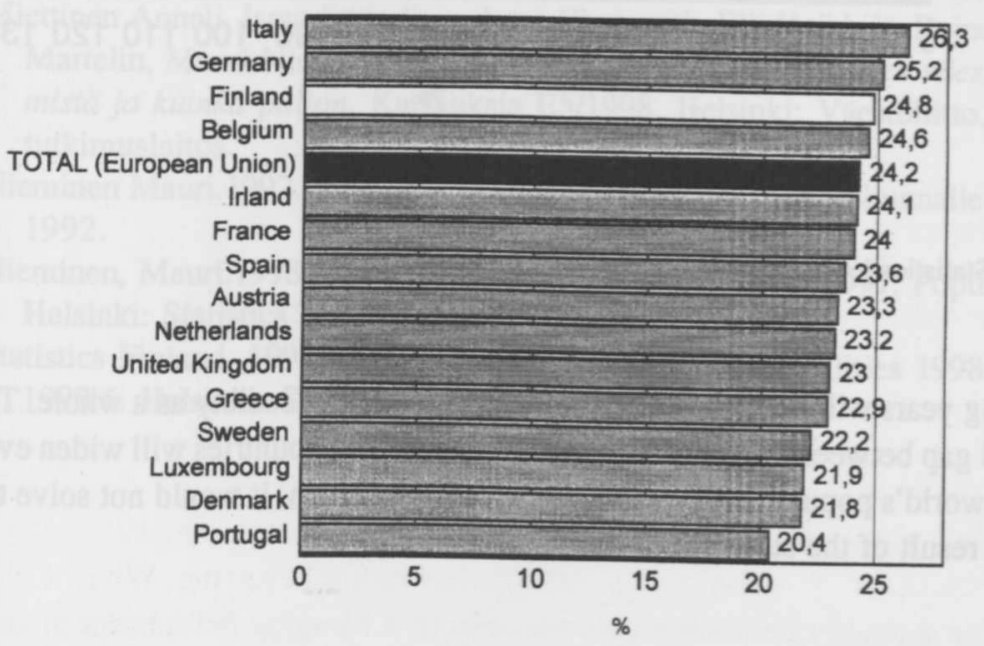

Source: Demographic Statistics 1996, Eurostat, Luxembourg 1996

The number of old persons grows at different rates in different countries. Sweden, for example, already has the most aged population of the EU countries, but the growth in the number of old persons there will be modest. In contrast, in Ireland, Luxembourg and the Netherlands, the number of old persons is forecast to double. After these three countries, the next largest growth in the number of old persons will occur in Finland, where it is forecast to have increased by 84 percent from today's figure by the year 2030 . 
Figure 3. Growth in the number of old persons in EU countries, 1995-2030, \%

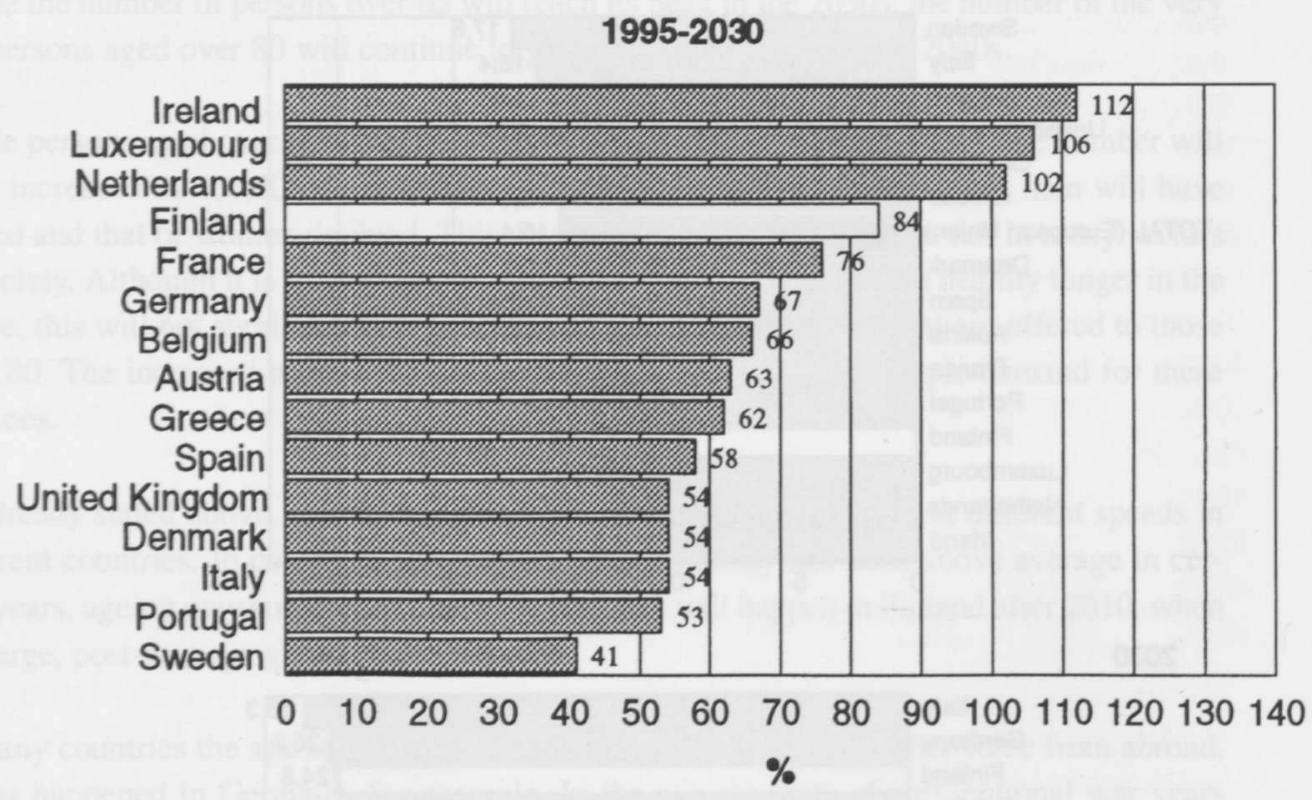

Source: Demographic Statistics 1996, Eurostat Luxembourg 1996

All in all, the coming years will be significant to the development of society as a whole. The economic and social gap between the industrialised and developing countries will widen even further. Even if the world's population growth could be slowed down, it would not solve the problems that are a result of the structure of the population.

\section{Aging population and society}

When the population ages at the speed it is doing in Finland today, for example, our social policies face a totally new challenge. The ageing of the population naturally leads to an increase in the demand for those services that are targeted directly to old people. A watertight social security system has been developed in Finland over the past years, which follows a person from cradle to grave. The system was created at a time when there was no shortage of payers and nobody saw that in a couple of decades the Finnish age structure would be totally different from what it is today. There will certainly be a much larger proportion of the population on the side of those being cared for than on that of the carers. In addition, a vast majority of those needing care will also be pensioners. 
Although pensioners have in their time stored up contributions for their pensions, they will not be adequate to maintain the kind of pension security system we have today. Financial contributions will also be required from persons of working age. These contributions are obtained through taxation, but there are also many other claimants to the revenue that is collected through taxation. The development of our age structure will influence increasingly the decisions that are made about who should benefit from the tax money in this country. In the final analysis, these are matters which must be decided at the political level.

\section{References:}

Eurostat. 1996. Demographic statistics 1996.

Korkiasaari Jouni and Ismo Söderling. 1994. Muuttoliike (migration). In: Suomen väestö, edited by Seppo Koskinen, Tuija Martelin, Irma-Leena Notkola, Veijo Notkola and Kari Pitkänen, pp. 226-264. Helsinki: Gaudeamus.

Miettinen Anneli, Ismo Söderling, Anna Ehrnrooth, Elli Heikkilä, Reino Hjerppe, Tuija Martelin, Mauri Nieminen ja Riikka Shemeikka (ed.). Suomen väestö 2031 - Miten, mistä ja kuinka paljon. Katsauksia E5/1998. Helsinki: Väestöliitto, Väestöntutkimuslaitos.

Nieminen Mauri.1992. Suomen väestönkehitys - haaste yhteiskunnalle, TTT Katsaus 4/ 1992.

Nieminen, Mauri.1998. Aliens and international migration 1997. Population 1998:8. Helsinki: Statistics Finland.

Statistics Finland. 1998. Population projection by municipalities 1998-2030. Population 1998:6. Helsinki: Statistics Finland. 